Sharif University of Technology
Scientia Iranica
SCIENTIA
I RAN I CA
http://scientiairanica.sharif.edu

\title{
Efficient multi-objective optimization algorithms for construction site layout problem
}

\author{
A. Kaveh ${ }^{\mathrm{a}, *}$, M. Rastegar Moghaddam ${ }^{\mathrm{b}}$, and M. Khanzadi ${ }^{\mathrm{b}}$ \\ a. Centre of Excellence for Fundamental Studies in Structural Engineering, Iran University of Science and Technology, Narmak, \\ Tehran, P.O. Box 16846-13114, Iran. \\ b. School of Civil Engineering, Iran University of Science and Technology, Narmak, Tehran, P.O. Box 16846-13114, Iran.
}

Received 26 November 2016; accepted 24 April 2017

\author{
KEYWORDS \\ Site construction \\ layout problems; \\ Multi-objective \\ optimization; \\ Colliding bodies \\ optimization; \\ Data envelopment \\ analysis; \\ Optimal Pareto front.
}

\begin{abstract}
Construction site layout planning is one of the managerial aspects of the construction industry and has a significant impact on performance of the sites. Since many objectives are involved in real site layout optimization, multi-objective algorithms are required. In this study, multi-objective versions of two meta-heuristics, CBO and ECBO, are developed, and their applicability and performances are checked within a case study. The quality of the results obtained verifies the ability of these algorithms to find the optimal Pareto front in this problem. Another tool utilized in this study is Data Envelopment Analysis (DEA) which, by calculating the efficiency of optimal Pareto front layouts, can help decision-makers select the final layout among the candidates. It should be mentioned that the DEA has previously been used in models with multiple inputs and outputs.
\end{abstract}

(C) 2018 Sharif University of Technology. All rights reserved.

\section{Introduction}

There are numerous managerial aspects in the construction industry, one of which is the Construction Site Layout Planning (CSLP). A proper site layout has considerable impacts on financial issue, construction quality, productivity, security, safety, and environmental effects [1]. This is why so many endeavors have been made in this field.

Construction site layout planning comprises three steps. First, the type and number of facilities, which are required for construction activities and services, should be determined. In the second step, the sizes of these facilities should be estimated. In the third step, optimum locations for the facilities must be found

\footnotetext{
*. Corresponding author. Tel.: +9821 77240104; Fax: +98 21 r7240398

E-mail address: alikaveh@iust.ac.ir (A. Kaveh).
}

doi: $10.24200 /$ sci. 2017.4216 to satisfy the considered objectives during the project lifetime [2]. This paper is focused on the latter step.

In the previous researches, construction site layout models have been often optimized for singleobjective functions such as minimizing the frequency of trips made by construction personnel [3,4] and minimizing the total transportation costs of resources between facilities [5,6]. However, in fact, there are different factors with influence on planning a proper layout; hence, the problem requires to be formulated as a multi-objective optimization. $\mathrm{Xu}$ and $\mathrm{Li}$ [7] maximized the distance between high risk and high protection facilities to decrease the corresponding accident. Yahya and Saka [8] considered a safety and environmental function that is constructed by a closeness relationship weight matrix. Hammad et al. [9] proposed a function which calculates the noise levels produced by various activities at multiple receivers in the vicinity of a construction site. Khalafallah and El-Rayes et al. [10] presented three distinct criteria: safety of crane, control of hazardous material, and travel routes 
intersection criteria. Afterwards, they were aggregated and formed as a safety index for evaluating the safety performance of construction sites.

The CSLP optimization has always been a challenging problem and is known to be an NP-Complete problem; besides, it becomes more complicated in large-scale sites. Thus, meta-heuristic algorithms are preferred to be utilized instead of exact optimization methods [11]. Literature reviews show that many papers have been published which concern the application of Genetic Algorithms (GA) [3,6,12], Ant Colony Optimization (ACO) [13,14], Simulated Annealing (SA), Particle Swarm Optimization (PSO) $[4,7,15,16]$, Particle-Bee Algorithm (PBA) [17], Harmony Search (HS) [18], and Colliding Bodies Optimization (CBO) [19] for solving single-objective CSLP problems.

In the case of multi-objective, researchers have also utilized some algorithms for obtaining an optimal set of solutions called Pareto front for multiobjective CSLP problems such as Multi-Objective Particle Swarm Optimization (MOPSO) [7], Nondominated Sorting Genetic Algorithm (NSGA-II) [10], Multi-Objective Artificial Bee Colony (MOABC) [8], and Multi-Objective Ant Colony Optimization algorithm (MOACO) [20]. $\mathrm{Xu}$ and $\mathrm{Li}$ [7] applied the MOPSO to optimize the dynamic site layout of Longtan hydropower project under fuzzy random environment. El-Rayes et al. [10] optimized their trade-off model between safety and cost by NSGA-II. Ning et al. [20] designed a decision-making system for solving dynamic, unequal-area, and multi-objective CSLP problems. The optimization phase of this system was executed by a modified pareto-based ant colony optimization algorithm. In addition, Yahya and Saka [8] compared the performances of the MOABC via Levy flights and basic MOABC and Max-Min Ant System (MMAS) for dynamic and multi-objective problems.

After generating the optimal Pareto front by various methods, project managers have to select one layout from alternatives for implementation in the site. The intuitionistic fuzzy TOPSIS method is a tool employed to evaluate and select a construction site layout [20]. Azadeh et al. [21] employed Data Envelopment Analysis (DEA) for calculating the efficiency of the considered maintenance workshop layout of a gas transmission unit; then, these alternative layouts were ranked and the most efficient layout was specified.

In this paper, the multi-objective versions of two recently developed meta-heuristic algorithms, known as Colliding Bodies Optimization (CBO) and Enhanced Colliding Bodies Optimization (ECBO), are developed and employed for solving multi-objective construction site layout problems. The CBO has been developed by Kaveh and Mahdavi [22] and ECBO by Kaveh and Ilchi Ghazaan [23]. Data Envelopment Analysis (DEA) is a nonparametric and linear programming method for calculating the efficiency of the units with multiple inputs and outputs. In order to determine the efficiency of different layout alternatives, DEA is applied to our model. The performance and applicability of the mentioned meta-heuristic algorithms and DEA technique are demonstrated within a case study, and results are compared with those of the MOPSO. The rest of this paper is organized as follows: in Section 2, our methodology, which includes optimization algorithms and DEA method, is described in detail. In Section 3, the case study and corresponding results are explained; finally, the concluding remarks are presented in Section 4.

\section{Methodology}

\subsection{Optimization meta-heuristic algorithms}

As mentioned in the previous section, in this research, multi-objective versions of two recently developed meta-heuristic algorithms have been used: CBO and ECBO. This section elaborates on colliding bodies optimization and its concept. In the following, some changes are applied to the structure of the CBO, and the multi-objective version of algorithm is developed.

The ECBO algorithm, together with some modifications, improved the basic CBO to make it faster in convergence speed and to obtain a better solution. Moreover, this modification is implemented on a multiobjective $\mathrm{CBO}$ and rendered enhanced multi-objective CBO.

\subsubsection{Colliding bodies optimization}

Colliding Bodies Optimization (CBO) is a recently developed population-based meta-heuristic algorithm [22]. This algorithm is inspired by nature, specifically from one-dimensional collisions between bodies. The collision process is based on laws from the physics. These laws and theories of algorithm are explained in the following section. All of the explanations about this method are extracted from Ref. [22].

\section{One-dimensional collision laws}

In nature, collisions between bodies occur based on two laws of physics: the laws of conservation of momentum and energy. These two laws are conserved in an isolated system while the collision is happening. The following equations express the aforementioned conservations:

$$
\begin{aligned}
& m_{1} \nu_{1}+m_{2} \nu_{2}=m_{1} \nu_{1}^{\prime}+m_{2} \nu_{2}^{\prime}, \\
& \frac{1}{2} m_{1} \nu_{1}^{2}+\frac{1}{2} m_{2} \nu_{2}^{2}=\frac{1}{2} m_{1} \nu_{1}^{\prime 2}+\frac{1}{2} m_{2} \nu_{2}^{\prime 2}+Q,
\end{aligned}
$$

where $\nu_{1}$ and $\nu_{2}$ are the initial velocities of the first and second bodies before collision, respectively. Final velocities of bodies after collision are represented by $\nu_{1}^{\prime}$ 
and $\nu_{2}^{\prime}$. Mass of the first body is $m_{1}$, mass of the second body is $m_{2}$, and $Q$ is lost energy caused by collision. Velocities of the bodies can be calculated by Eqs. (3) and (4) as follows:

$$
\begin{aligned}
& \nu_{1}^{\prime}=\frac{\left(m_{1}-\varepsilon m_{2}\right) \nu_{1}+\left(m_{2}+\varepsilon m_{2}\right) \nu_{2}}{\left(m_{1}+m_{2}\right)}, \\
& \nu_{2}^{\prime}=\frac{\left(m_{2}-\varepsilon m_{1}\right) \nu_{2}+\left(m_{1}+\varepsilon m_{1}\right) \nu_{1}}{\left(m_{1}+m_{2}\right)},
\end{aligned}
$$

where $\varepsilon$ is the Coefficient Of Restitution (COR) and indicates the ratio of the relative velocity of separation to the relative velocity of approach between two colliding bodies. Depending on the type of the collision, elastic or inelastic collision, the value of $\varepsilon$ can be one $\varepsilon=1$ or between zero and unity $0<\varepsilon<1$.

The CBO algorithm mechanism

The CBO starts with a population of random Colliding Bodies (CB). Each CB is known as a solution candidate and has specific mass. The mass of CBs can be specified according to their fitness values by the following formula:

$$
m_{k}=\frac{\frac{1}{\mathrm{fit}(k)}}{\frac{1}{\sum_{i=1}^{n} \frac{1}{\mathrm{fit}(i)}}}, \quad k=1,2, \ldots, n,
$$

where fit $(i)$ represents the fitness values of the $i$ th $C B$, and $n$ is the number of colliding bodies.

The CBs are sorted out due to their fitness values in an ascending order and divided into two equal groups: stationary and moving groups. The lower and upper halves of the CBs represent stationary and moving groups. The moving CBs move toward stationary CBs, and a collision occurs between pairs of CBs.

The initial velocities of stationary and moving CBs are specified by:

$$
\begin{aligned}
& \nu_{i}=0, \quad i=1,2, \ldots, \frac{n}{2}, \\
& \nu_{i}=x_{i-\frac{n}{2}}-x_{i}, \quad i=\frac{n}{2}+1, \frac{n}{2}+2, \ldots, n,
\end{aligned}
$$

where $\nu_{i}$ and $x_{i}$ are the velocity and location vector of the $i$ th $\mathrm{CB}$ in this group, respectively; $x_{i-\frac{n}{2}}$ is the $i$ th CB pair location of $x_{i}$ in the previous group.

After the collision, the velocities of the stationary and moving $\mathrm{CBs}\left(\nu_{i}^{\prime}\right)$ are evaluated by:

$$
\begin{aligned}
& \nu_{i}^{\prime}=\frac{\left(m_{i+\frac{n}{2}}+\varepsilon m_{i+\frac{n}{2}}\right) \nu_{i+\frac{n}{2}}}{m_{i}+m_{i+\frac{n}{2}}}, \quad i=1,2, \ldots, \frac{n}{2}, \quad \text { (8) } \\
& \nu_{i}^{\prime}=\frac{\left(m_{i}-\varepsilon m_{i-\frac{n}{2}}\right) \nu_{i}}{m_{i}+m_{i-\frac{n}{2}}}, \quad i=\frac{n}{2}+1, \frac{n}{2}+2, \ldots, n, \\
& \varepsilon=1-\frac{\text { iter }}{\text { iter }_{\text {max }}},
\end{aligned}
$$

where iter and iter $\max$ are the current iteration number and the total number of iteration for optimization process, respectively, and $\varepsilon$ is the Coefficient Of Restitution (COR). In addition, updated locations of the CBs are calculated as follows:

$$
\begin{aligned}
& x_{i}^{\text {new }}=x_{i}+\operatorname{rand}^{\circ} \nu_{i}^{\prime}, \quad i=1,2, \ldots, \frac{n}{2}, \\
& x_{i}^{\text {new }}=x_{i-\frac{n}{2}}+\operatorname{rand}^{\circ} \nu_{i}^{\prime}, \quad i=\frac{n}{2}+1, \frac{n}{2}+2, \ldots, n,
\end{aligned}
$$

where $x_{i}^{\text {new }}, x_{i}$, and $\nu_{i}^{\prime}$ are the new locations, previous locations, and the velocity after the collision of the $i$ th $\mathrm{CB}$, respectively. rand represents a random vector uniformly distributed in the range of $[-1,1]$.

This process of the $\mathrm{CBO}$ algorithm is repeated repeatedly until a termination criterion, such as maximum iteration number, is satisfied.

\subsubsection{Non-dominated sorting colliding bodies optimization}

The CBO algorithm is originally a single-objective method and cannot be employed in problems with more than one objective function; however, with some changes, it can be changed to a multi-objective algorithm. The most serious change necessary to make in sorting is using the non-dominated sorting approach instead of regular sorting according to the function values.

Deb et al. presented this approach for the first time [24] and utilized it in NSGA-II. Its pseudo code is presented in Figure 1. By performing this algorithm on CBs, bodies are assigned to separate fronts. Number of each front is considered as the rank of the CBs. For prioritizing CBs in each front, Crowding Distance (CD) should be calculated for bodies. CD is another concept which is used in NSGA-II [24]. CD performs this task according to the diversity of CBs in a front, i.e. solitude solution has higher priority compared to the other solutions in the same front.

For each solution, crowding distance is calculated by:

$$
\mathrm{CD}^{i}=\sum_{j=1}^{k} \frac{\left|f_{j}^{i+1}-f_{j}^{i-1}\right|}{f_{j}^{\max }-f_{j}^{\min }}, \quad j=1, . ., k
$$

where $f_{j}^{i+1}$ and $f_{j}^{i-1}$ represent the $j$ th function value of the $(i+1)$ th and $(i-1)$ th $\mathrm{CB}$ in the considered front, respectively. Moreover, $f_{j}^{\max }$ and $f_{j}^{\min }$ are the maximum and minimum values of the $j$ th function, respectively.

In this algorithm, the magnitude of the mass for each $\mathrm{CB}$ is calculated by using the rank and $\mathrm{CD}$ values of the CBs by Eq. (14):

$$
m_{k}=\frac{\frac{1}{\operatorname{Rank}(k)+\frac{1}{\mathrm{CD}(k)}}}{\sum_{i=1}^{n} \frac{1}{\operatorname{Rank}(i)+\frac{1}{\mathrm{CD}(i)}}}, \quad k=1,2, \ldots, n .
$$




\begin{tabular}{|c|c|}
\hline for each $p \in P$ & $P$, is considered population \\
\hline$S_{p}=\phi$ & $\begin{array}{l}\text { The set of solutions, that } p \\
\text { dominates }\end{array}$ \\
\hline$n_{p}=0$ & $\begin{array}{l}\text { The number of solutions } \\
\text { which dominate } p\end{array}$ \\
\hline for each $q \in P$ & \\
\hline if $(p \prec q)$ then & If $p$ dominates $q$ \\
\hline $\begin{array}{l}\qquad S_{p}=S_{p} \cup\{q\} \\
\text { else if }(q \prec p) \text { then }\end{array}$ & Add $q$ to $S_{p}$ \\
\hline$n_{p}=n_{p}+1$ & $\begin{array}{l}\text { Increment the domination } \\
\text { counter of } p\end{array}$ \\
\hline $\begin{array}{l}\text { if } n_{p}=0 \text { then } \\
p_{\text {rank }}=1 \\
F_{1}=F_{1} \bigcup\{p\}\end{array}$ & $p$ belongs to the first front \\
\hline $\begin{array}{l}i=1 \\
\text { while } F_{i} \neq \phi\end{array}$ & Initialize the front counter \\
\hline$Q=\phi$ & $\begin{array}{l}\text { Used to store the members } \\
\text { of the next front }\end{array}$ \\
\hline $\begin{array}{l}\text { for each } p \in F_{i} \\
\qquad \begin{array}{c}\text { for each } q \in S_{p} \\
n_{q}=n_{q}-1\end{array}\end{array}$ & \\
\hline $\begin{array}{l}\text { if } n_{q}=0 \text { then } \\
q_{\text {rank }}=i+1 \\
Q=Q \bigcup\{q\}\end{array}$ & $q$ belongs to the next front \\
\hline$i=i+1$ & \\
\hline$F_{i}=Q$ & \\
\hline
\end{tabular}

Figure 1. Pseudocode of non-dominated sorting [24].

Other steps and details are the same as those of the CBO. The flowchart of the NSCBO algorithm is depicted in Figure 2.

\subsubsection{Enhanced non-dominated sorting colliding bodies optimization}

Having considered two modifications, Kaveh and Ilchi Ghazaan [23] improved the standard CBO in quality of the solutions and convergence speed and called it ECBO. The first modification involved using a memory to save the best-found solution, and the second modification involved utilizing a mechanism to escape from local optimum. In this mechanism, a parameter like Pro within $(0,1)$ was set and, for each CB, Pro was compared with $r n_{i}(i=1,2, \ldots, n)$, which is a random number between 0 and 1 . If $r n_{i}<$ Pro, a random variable $(j)$ of the $i$ th $\mathrm{CB}$ was selected and altered as follows:

$$
x_{i j}=x_{j, \min }+\operatorname{random} \cdot\left(x_{j, \max }-x_{j, \min }\right) .
$$

Further explanations and applications of the $\mathrm{CBO}$ and ECBO can be found in recent books by Kaveh $[25,26]$.

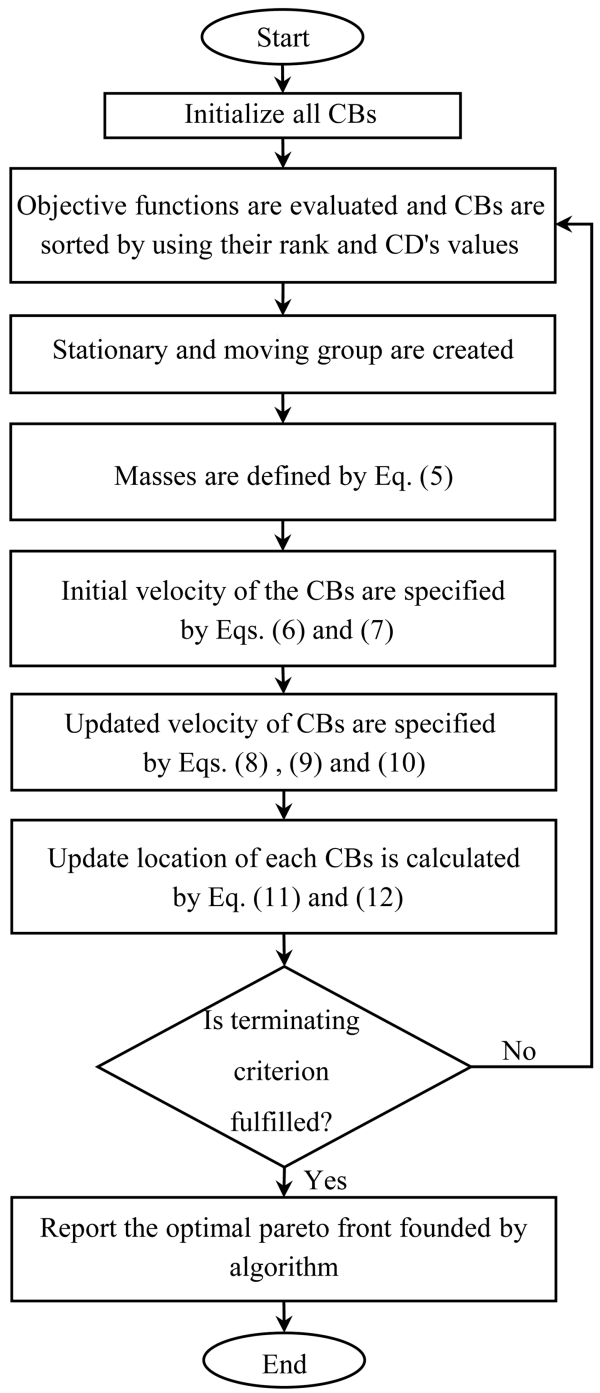

Figure 2. Flowchart of the NSCBO algorithm.

In order to improve the performance of the $\mathrm{NSCBO}$, these modifications are applied to it and created a modified version of the NSCBO, which is called ENSCBO. The flowchart of the ENSCBO algorithm is depicted in Figure 3.

\subsection{Data envelopment analysis}

Data Envelopment Analysis (DEA) is a non-parametric and linear programming method in operations research and economics to estimate the efficiency of DecisionMaking Units (DMUs) with multiple inputs and outputs. This method is based on the ideas of Farrell [27]. One of the most basic models of the DEA is CCR model developed by Charnes, Cooper, and Rhodes [28]. This method calculated the relative efficiency of each DMU with $S$ outputs and $m$ inputs by the following formula:

$$
\max \theta_{k}=\frac{\sum_{i=1}^{s} u_{i} y_{i k}}{\sum_{j=1}^{m} \nu_{j} x_{j k}}
$$

s.t. 


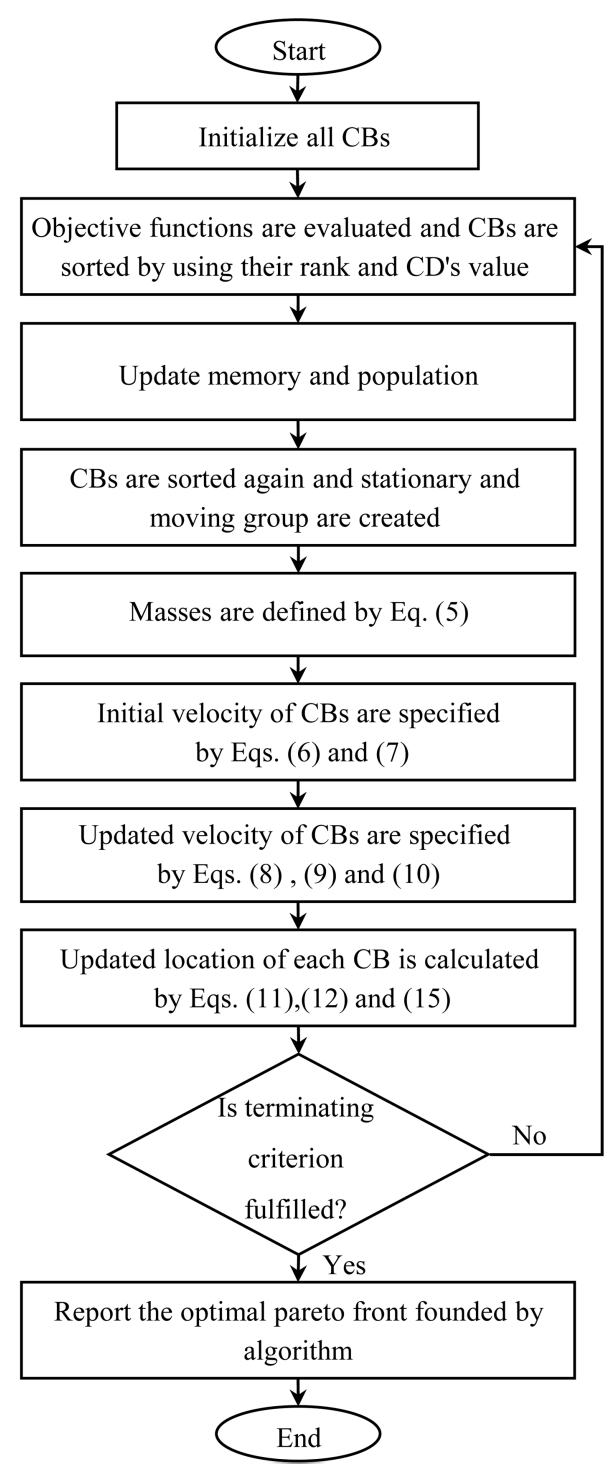

Figure 3. Flowchart of the ENSCBO.

$$
\begin{aligned}
& \theta_{1}=\frac{\sum_{i=1}^{s} u_{i} y_{i l}}{\sum_{j=1}^{m} \nu_{j} x_{j l}} \leq 1, \quad l=1,2, \ldots, n, \\
& u_{i}, \nu_{j} \geq 0
\end{aligned}
$$

where $\theta_{K}$ is the efficiency of the $\mathrm{DMU}_{k}, y_{j l}$ and $x_{j l}$ are the outputs and inputs of the $\mathrm{DMU}_{i}$, respectively. $u_{i}$ and $\nu_{r}$ are the proper weights of inputs and outputs. Since linear programming cannot handle fraction, its formulation should change, such that denominator of the fraction is limited and only the linear programming is allowed to maximize the numerator. Therefore, the CCR model ought to be transformed into the following formula:

$$
\max \sum_{i=1}^{s} u_{i} y_{i k},
$$

s.t.

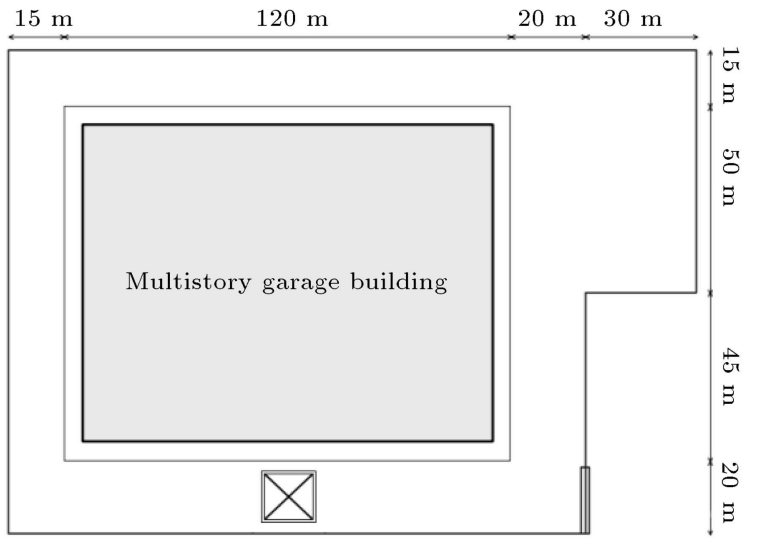

Figure 4. Form and dimensions of the site.

\begin{tabular}{|c|c|c|c|}
\hline Index & Temporary facilities & $\begin{array}{c}\text { Length } \\
(\mathrm{m})\end{array}$ & $\begin{array}{c}\text { Width } \\
(\mathrm{m})\end{array}$ \\
\hline F1 & Parking lot & 20 & 20 \\
\hline $\mathrm{F} 2$ & Office 1 & 20 & 5 \\
\hline F3 & Office 2 & 20 & 5 \\
\hline F4 & Office 3 & 20 & 5 \\
\hline F5 & Office 4 & 20 & 5 \\
\hline F6 & Workshop & 5 & 4 \\
\hline F7 & Storage 1 & 6 & 5 \\
\hline F8 & Storage 2 & 4 & 5 \\
\hline F9 & Electric generator & 2 & 2 \\
\hline F10 & Toilets & 5 & 6 \\
\hline F11 & Fire station & 3 & 3 \\
\hline $\mathrm{F} 12$ & Inflammable materials storage & 3 & 3 \\
\hline \multicolumn{4}{|c|}{$\sum_{j=1}^{m} \nu_{j} x_{j k}=1$} \\
\hline$\sum_{i=1}^{s} u$ & $y_{i l}-\sum_{j=1}^{m} \nu_{j} x_{j l} \leq 0$ & $2, \ldots, n$ & \\
\hline$u_{i}, \nu_{j}$ & 0 & & (17) \\
\hline
\end{tabular}

Table 1. Temporary facilities and the associated dimensions.

\section{Case study and discussion of results}

\subsection{Description of the case study}

One case study is selected to determine the performance of the considered multi-objective algorithm. The chosen case is taken from Ref. [10]. This case study is a multi-story garage building with the form and dimensions as illustrated in Figure 4. Facilities, associated dimensions, and center of coordinate for the fixed facilities are listed in Tables 1 and 2. The purpose of this case study is to properly locate the temporary facilities in the available spaces to achieve the considered objectives. 
Table 2. Fixed facilities and their dimensions and coordinates.

\begin{tabular}{clcccc}
\hline Index & Fixed facilities & Length $(\mathbf{m})$ & Width $(\mathbf{m})$ & $\boldsymbol{X}$ coordinate & $\boldsymbol{Y}$ coordinate \\
\hline C1 & Multistory garage building & 120 & 95 & 75 & 67.5 \\
K2 & Tower crane & 15 & 15 & 75 & 10 \\
G3 & Entrance gate & - & - & 155 & 10 \\
\hline
\end{tabular}

Table 3. Transportation cost between the facilities.

\begin{tabular}{|c|c|c|c|c|c|c|c|c|c|c|c|c|c|c|c|}
\hline \multirow[b]{2}{*}{ Facility $i$} & \multicolumn{15}{|c|}{ Facility $j$} \\
\hline & F1 & F2 & F3 & F4 & F5 & F6 & F7 & F 8 & F9 & F10 & F11 & F12 & C1 & K1 & G1 \\
\hline F1 & 0 & - & - & - & - & - & - & - & - & - & - & - & - & - & - \\
\hline $\mathrm{F} 2$ & 4 & 0 & - & - & - & - & - & - & - & - & - & - & - & - & - \\
\hline F3 & 4 & $7.5^{*}$ & 0 & - & - & - & - & - & - & - & - & - & - & - & - \\
\hline $\mathrm{F} 4$ & 4 & $7.5^{*}$ & $7.5^{*}$ & 0 & - & - & - & - & - & - & - & - & - & - & - \\
\hline F5 & 4 & 5.5 & 5.5 & 2.5 & 0 & - & - & - & - & - & - & - & - & - & - \\
\hline F6 & 1.5 & 1 & 1 & 1 & 1 & 0 & - & - & - & - & - & - & - & - & - \\
\hline F7 & 1.5 & 1 & 1 & 1 & 1 & $9.5^{*}$ & 0 & - & - & - & - & - & - & - & - \\
\hline F8 & 1.5 & 1 & 1 & 1 & 1 & $9.5^{*}$ & 6.5 & 0 & - & - & - & - & - & - & - \\
\hline F9 & 1.5 & 2 & 1 & 3 & 3 & 3 & 3 & 3 & 0 & - & - & - & - & - & - \\
\hline F10 & 1.5 & $7.5^{*}$ & $7.5^{*}$ & $7.5^{*}$ & $7.5^{*}$ & 6.5 & 6.5 & 6.5 & 1 & 0 & - & - & - & - & - \\
\hline F11 & 1.5 & 1 & 1 & 1 & 1 & 1 & 1 & 1 & 1 & 1 & 0 & - & - & - & - \\
\hline F12 & 1.5 & 1 & 1 & 1 & 1 & 3.5 & 1 & 1 & 3.5 & 1 & 1 & 0 & - & - & - \\
\hline $\mathrm{C} 1$ & 1.5 & 3.5 & 3.5 & 3.5 & 3.5 & 6.5 & 4.5 & 4.5 & 5.5 & 3 & 1 & 4.5 & 0 & - & - \\
\hline K1 & 0 & $7.5^{*}$ & 5.5 & $7.5^{*}$ & $7.5^{*}$ & $9.5^{*}$ & $9.5^{*}$ & $9.5^{*}$ & 0 & 0 & 1 & 4.5 & 5 & 0 & - \\
\hline G1 & 1.5 & 0 & 0 & 0 & 0 & 3 & $7^{*}$ & $7^{*}$ & 0 & 0 & 0 & 1 & 0 & 0 & 0 \\
\hline
\end{tabular}

*: Crowded routes.

\subsubsection{Objective functions}

This case study has two objective functions. The first one is minimization of the resource transportation costs between facilities calculated as follows:

$$
\text { Minimize } \mathrm{TC}=\sum_{i=1}^{I-1} \sum_{j=i+1}^{I}\left(C_{i j} \times d_{i j}\right),
$$

where $C_{i j}$ represents the transportation cost per unit distance between facilities $i$ and $j$ in Table 3 , and $d_{i j}$ is the distance between these facilities.

The second objective of this case study is maximization of the site safety condition that consists of three individual criteria known as the Crane Safety Criteria (CSC), the Normalized Hazards Control Criterion (NHCC), and the Intersection Point Criterion (IPC). The CSC can be operational according to facilities' positions (in Table 4), sensitivity to falling objects provided in Table 5, and the ratio between the risks of falling objects to crane collapse $(m)$. This criterion is calculated by Eqs. (19) and (20) as follows:

$$
\mathrm{CSC}=\frac{\sum_{k=1}^{k} \frac{\sum_{I=1}^{I} \mathrm{CS}_{i k}}{I}}{k},
$$

$$
\begin{aligned}
& \mathrm{CS}_{i k}= \\
& \left\{\begin{aligned}
\mathrm{CS}_{i k}^{1}= & \left\{\begin{array}{l}
0 \%\left(V_{i}=\text { high }\right) \\
25 \%\left(V_{i}=\text { medium }\right) \\
50 \%\left(V_{i}=\text { low }\right)
\end{array} \quad\right. \text { (Zone 1) } \\
\mathrm{CS}_{i k}^{2^{*}}= & \left.100-\frac{100-C S_{i k}^{1}}{m} \quad \text { (Zone } 2^{*}\right) \\
\mathrm{CS}_{i k}^{2}= & \left(100-\mathrm{CS}_{i k}^{2^{*}}\right) \times\left(\frac{d_{i k}-j-M / 2}{H}\right) \\
& +\mathrm{CS}_{i k}^{2^{*}} \\
\mathrm{CS}_{i k}^{3}= & 100 \%\left(V_{i}\right. \\
= & \text { high, medium, or low) } \quad \text { (Zone 3) }
\end{aligned}\right.
\end{aligned}
$$

Control of the hazardous material is another factor evaluated by Eq. (21) and, then, normalized by Eq. (22):

$$
\begin{aligned}
& \mathrm{HCC}=\sum_{i=1}^{I-1} \sum_{j=i+1}^{I} \mathrm{HCW}_{i j} \times d_{i j}, \\
& \mathrm{NHCC}=\frac{\mathrm{HCC}-\mathrm{HCC}_{\min }}{\mathrm{HCC}_{\max }-\mathrm{HCC}_{\min }},
\end{aligned}
$$


Table 4. Zone classifications.

\begin{tabular}{cl}
\hline Range & Zone \\
\hline$d_{i k}<J+\frac{M}{2}, \quad \theta_{i} \in \theta_{f}$ & 1 \\
$J+\frac{M}{2} \leq d_{i k}<H+J+\frac{M}{2}$ & 2 \\
$d_{i k}<J+\frac{M}{2}, \quad \theta_{i} \in \theta_{u}$ & $2^{*}$ \\
$d_{i k} \geq H+J+\frac{M}{2}$ & 3 \\
\hline
\end{tabular}

Note: $J$ is the length of the crane $j i b ; M$ is the width of the crane mast; $H$ is the reach of the crane; $\theta_{f}$ is the operating angle; $\theta_{u}$ is the non-operating angle.

where $\mathrm{HCW}_{i j}$ is the hazard control weight between facilities $i$ and $j$, as presented in Table 6 . $\mathrm{HCC}_{\max }$ and $\mathrm{HCC}_{\text {min }}$ are the maximum and minimum values of the $\mathrm{HCC}$, respectively.

Finally, the third criterion is calculated by Eqs. (23) and (24). This criterion is based on decreasing the probability of the accidents on the crowded routes:

$$
\begin{aligned}
& \mathrm{IPC}=\left(1-\frac{\mathrm{IP}}{\mathrm{IP}_{\max }}\right) \times 100 \%, \\
& \mathrm{IP}_{\max }=\frac{\mathrm{NR} \times(\mathrm{NR}-1)}{2},
\end{aligned}
$$

where NR is the number of the crowded routes specified in Table 3, and IP is the number of intersection points of these routes.
The safety index is the combination of these three explained criteria, representing the estimation of the site safety condition. Thus, the second objective function is provided as follows:

$$
\text { Maximize } \mathrm{SI}=w_{1} \times \mathrm{CSC}+w_{2} \times \mathrm{NHCC}+w_{3} \times \mathrm{IPC} .
$$

The relative weights $w_{1}, w_{2}$, and $w_{3}$ are assumed to be $0.6,0.2$, and 0.2 in this case study, respectively.

\subsection{Result and discussions}

The above-mentioned case study problem was solved by NSCBO and ENSCBO algorithms, and the results were compared with a robust algorithm, MOPSO. The results of running the algorithms with 1000 iterations are shown in Figures 5, 6, and 7 for the MOPSO, NSCBO, and ENSCBO algorithms, respectively. For a better comparison, the found Pareto fronts are shown in Figure 8.

As observed, the ENSCBO has found safer and less expensive layouts. In other words, it has found a better Pareto front that includes a wider range of cost and safety compared to the other two algorithms. In addition, the NSCBO has a slightly better performance in comparison with MOPSO. In Figures 9 and 10, the lowest cost and safest layouts are depicted, respectively. As observed from Figure 9, the proximity of facilities and locating them in the high-risk zone of crane led to the computation of low safety index. However, the

Table 5. Sensitivity of the facilities.

\begin{tabular}{ccccccccccccc}
\hline Facility $i$ & F1 & F2 & F3 & F4 & F5 & F6 & F7 & F8 & F9 & F10 & F11 & F12 \\
\hline Sensitivity $i$ & M & H & H & H & H & H & M & M & M & L & M & M \\
\hline
\end{tabular}

\begin{tabular}{|c|c|c|c|c|c|c|c|c|c|c|c|c|c|}
\hline \multirow[b]{2}{*}{ Facility $i$} & \multicolumn{13}{|c|}{ Facility $j$} \\
\hline & F1 & F2 & F3 & F4 & F5 & F6 & F7 & F8 & F9 & F10 & F11 & F12 & C1 \\
\hline F1 & $\mathrm{N}$ & - & - & - & - & - & - & - & - & - & - & - & - \\
\hline $\mathrm{F} 2$ & $\mathrm{~L}$ & $\mathrm{~N}$ & - & - & - & - & - & - & - & - & - & - & - \\
\hline F3 & $\mathrm{L}$ & $\mathrm{N}$ & $\mathrm{N}$ & - & - & - & - & - & - & - & - & - & - \\
\hline $\mathrm{F} 4$ & $\mathrm{~L}$ & $\mathrm{~N}$ & $\mathrm{~N}$ & $\mathrm{~N}$ & - & - & - & - & - & - & - & - & - \\
\hline F5 & $\mathrm{L}$ & $\mathrm{N}$ & $\mathrm{N}$ & $\mathrm{N}$ & $\mathrm{N}$ & - & - & - & - & - & - & - & - \\
\hline F6 & $\mathrm{M}$ & $\mathrm{M}$ & $\mathrm{M}$ & $\mathrm{M}$ & $\mathrm{M}$ & $\mathrm{N}$ & - & - & - & - & - & - & - \\
\hline F7 & $\mathrm{M}$ & $\mathrm{M}$ & $\mathrm{M}$ & $\mathrm{M}$ & $\mathrm{M}$ & $\mathrm{L}$ & $\mathrm{N}$ & - & - & - & - & - & - \\
\hline F8 & $\mathrm{M}$ & $\mathrm{M}$ & $\mathrm{M}$ & $\mathrm{M}$ & $\mathrm{M}$ & $\mathrm{L}$ & $\mathrm{N}$ & $\mathrm{N}$ & - & - & - & - & - \\
\hline F9 & $\mathrm{M}$ & $\mathrm{H}$ & $\mathrm{H}$ & $\mathrm{H}$ & $\mathrm{H}$ & $\mathrm{H}$ & $\mathrm{L}$ & $\mathrm{L}$ & $\mathrm{N}$ & - & - & - & - \\
\hline F10 & $\mathrm{N}$ & $\mathrm{N}$ & $\mathrm{N}$ & $\mathrm{N}$ & $\mathrm{N}$ & $\mathrm{N}$ & $\mathrm{L}$ & $\mathrm{L}$ & $\mathrm{L}$ & $\mathrm{N}$ & - & - & - \\
\hline F11 & $\mathrm{N}$ & $\mathrm{N}$ & $\mathrm{N}$ & $\mathrm{N}$ & $\mathrm{N}$ & $\mathrm{N}$ & $\mathrm{N}$ & $\mathrm{N}$ & $\mathrm{N}$ & $\mathrm{N}$ & $\mathrm{N}$ & - & - \\
\hline F12 & $\mathrm{H}$ & $\mathrm{M}$ & $\mathrm{M}$ & $\mathrm{M}$ & $\mathrm{M}$ & $\mathrm{L}$ & $\mathrm{N}$ & $\mathrm{N}$ & $\mathrm{V}$ & $\mathrm{N}$ & $\mathrm{N}$ & $\mathrm{N}$ & - \\
\hline $\mathrm{C} 1$ & $\mathrm{H}$ & $\mathrm{V}$ & $\mathrm{V}$ & $\mathrm{V}$ & $\mathrm{V}$ & $\mathrm{M}$ & $\mathrm{M}$ & $\mathrm{M}$ & $\mathrm{H}$ & $\mathrm{M}$ & $\mathrm{N}$ & $\mathrm{M}$ & $\mathrm{N}$ \\
\hline
\end{tabular}

Note: $\mathrm{H}=$ high, $\mathrm{M}=$ medium, $\mathrm{L}=$ low .

Table 6. Hazard control weight between the facilities. 


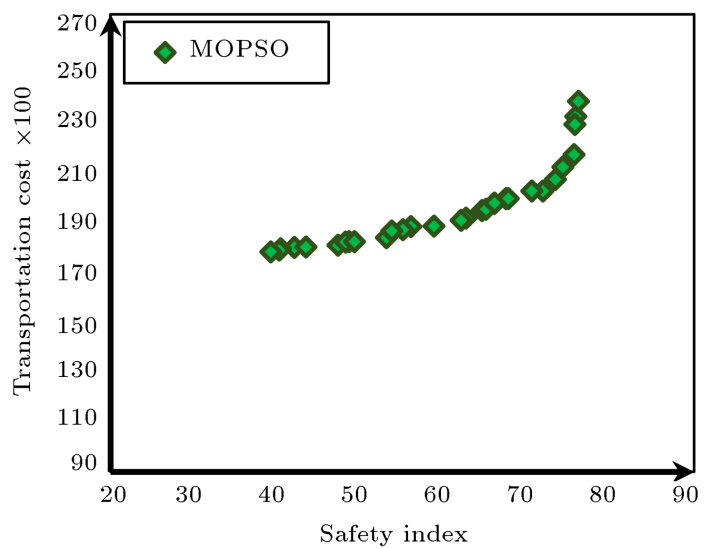

Figure 5. Pareto front obtained by the MOPSO.

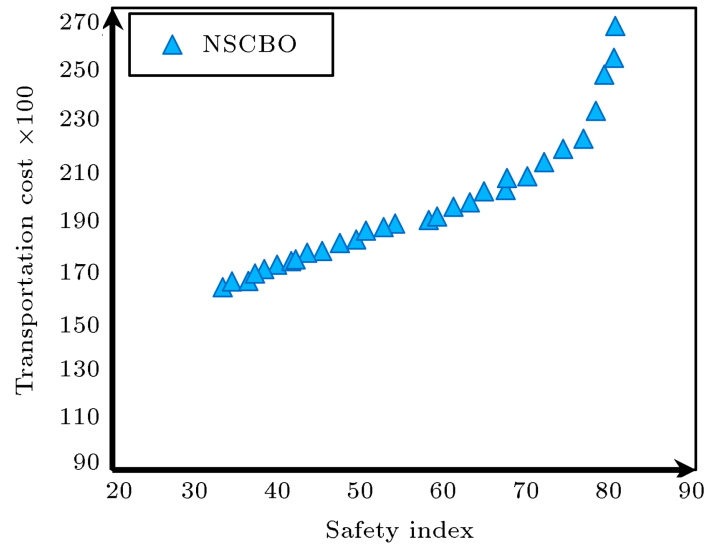

Figure 6. Pareto front obtained by NSCBO.

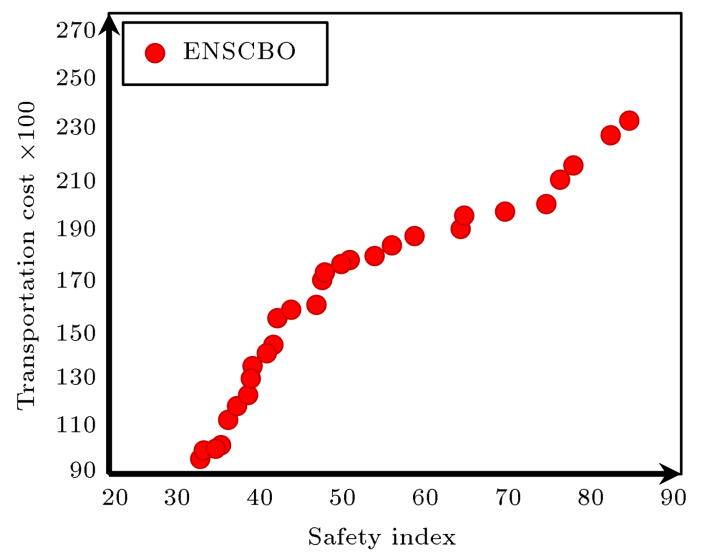

Figure 7. Pareto front obtained by the ENSCBO.

cost of this layout is the lowest compared to that of the others. The safety index of it is 31.18 and the corresponding cost is 9628.03 . On the contrary, in the layout shown in Figure 10, the facilities are located to ensure the highest safety level and an increase in the site transportation cost. The highest safety index is 83.68 and the corresponding cost is 23571.83. Other layouts represent a trade-off between cost and safety.

Choosing one layout from the found optimal

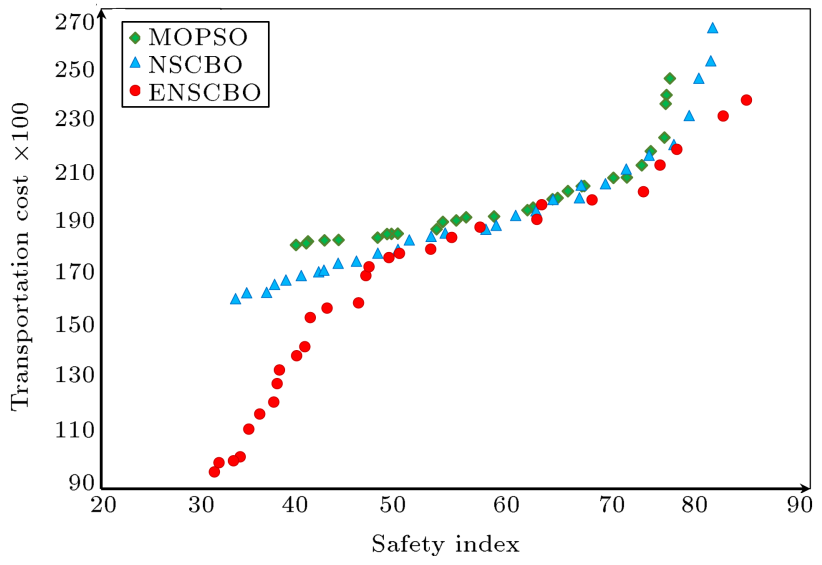

Figure 8. Compression of the algorithms.

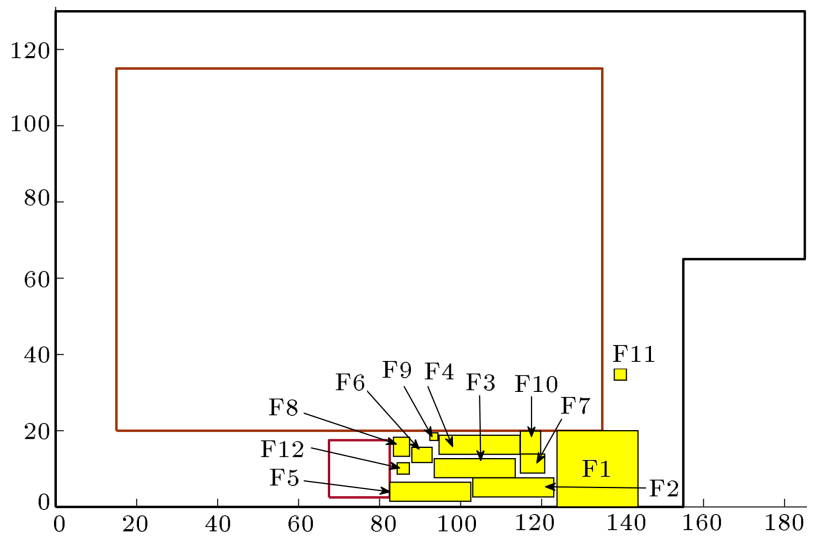

Figure 9. Layout with the lowest cost.

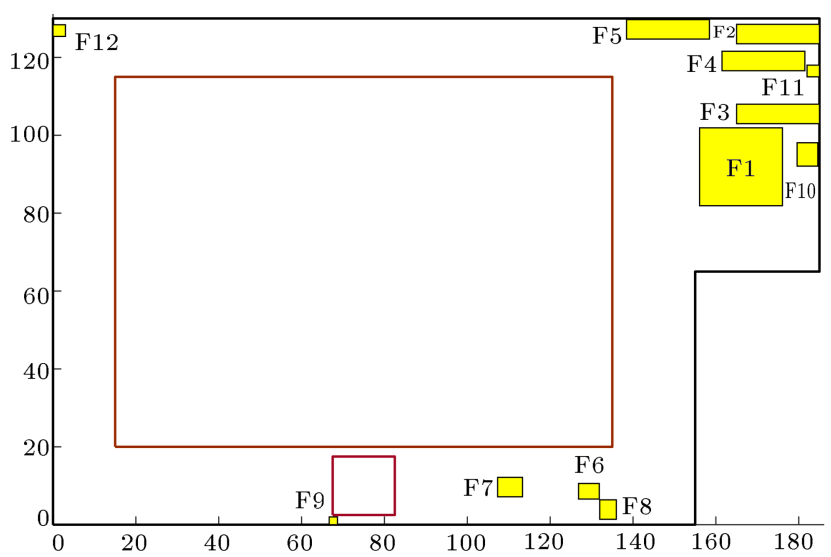

Figure 10. Safest layout.

Pareto front has always been a challenging issue for project managers. DEA is a tool that helps managers to select the best layout from alternatives by calculating the efficiency of each layout.

In this problem, each layout has been considered as a DMU, and the transportation cost and safety criteria have been considered as the inputs and outputs, respectively. Input and output of each layout and computed efficiencies of layouts with CCR model of 
Table 7. Input, outputs, and efficiency of the DMUs.

\begin{tabular}{|c|c|c|c|c|c|}
\hline \multirow{2}{*}{$\begin{array}{c}\text { Layout } \\
\text { alternative }\end{array}$} & \multirow{2}{*}{$\begin{array}{c}\text { Input } \\
\text { Transportation cost }\end{array}$} & \multicolumn{3}{|c|}{ Outputs } & \multirow{2}{*}{$\begin{array}{c}\text { Efficiency by } \\
\text { CCR }\end{array}$} \\
\hline & & $\mathrm{CSC}$ & NHCC & IPC & \\
\hline A & 23571.83 & 73.64 & 99.71 & 97.79 & 1 \\
\hline B & 9628.03 & 25.00 & 0.00 & 80.88 & 0.9959 \\
\hline $\mathrm{C}$ & 22975.02 & 69.57 & 99.78 & 98.53 & 1 \\
\hline $\mathrm{D}$ & 20135.68 & 65.64 & 75.13 & 95.59 & 1 \\
\hline $\mathrm{E}$ & 21137.20 & 66.43 & 83.15 & 93.38 & 0.9873 \\
\hline $\mathrm{F}$ & 11230.59 & 28.75 & 5.68 & 80.88 & 0.9202 \\
\hline G & 15971.13 & 34.68 & 40.58 & 82.35 & 0.8785 \\
\hline $\mathrm{H}$ & 18810.43 & 44.45 & 62.45 & 91.18 & 0.9384 \\
\hline I & 15417.46 & 28.75 & 30.89 & 86.03 & 0.8606 \\
\hline $\mathrm{J}$ & 11797.81 & 28.75 & 8.18 & 83.82 & 0.9018 \\
\hline $\mathrm{K}$ & 15776.24 & 30.79 & 38.96 & 80.15 & 0.8615 \\
\hline $\mathrm{L}$ & 10196.54 & 28.75 & 0.00 & 82.35 & 1 \\
\hline M & 12251.62 & 28.76 & 20.96 & 77.94 & 0.9119 \\
\hline $\mathrm{N}$ & 14325.30 & 32.91 & 17.93 & 83.82 & 0.8176 \\
\hline $\mathrm{O}$ & 13984.00 & 25.00 & 31.72 & 89.71 & 0.9851 \\
\hline $\mathrm{P}$ & 19102.02 & 51.86 & 63.87 & 95.59 & 0.9586 \\
\hline Q & 19830.62 & 65.47 & 56.87 & 88.97 & 1 \\
\hline $\mathrm{R}$ & 13448.64 & 28.75 & 14.20 & 87.50 & 0.8488 \\
\hline $\mathrm{S}$ & 18424.62 & 40.18 & 58.31 & 94.12 & 0.9486 \\
\hline $\mathrm{T}$ & 17984.41 & 38.78 & 54.37 & 91.91 & 0.9318 \\
\hline $\mathrm{U}$ & 21725.40 & 69.91 & 78.80 & 95.59 & 0.9863 \\
\hline $\mathrm{V}$ & 16994.76 & 30.68 & 45.91 & 92.65 & 0.9307 \\
\hline $\mathrm{W}$ & 9975.07 & 25.00 & 0.01 & 83.09 & 0.9785 \\
\hline $\mathrm{X}$ & 19653.37 & 52.41 & 67.54 & 92.65 & 0.9377 \\
\hline $\mathrm{Y}$ & 10046.91 & 25.00 & 3.55 & 86.76 & 1 \\
\hline $\mathrm{Z}$ & 12944.14 & 28.75 & 14.49 & 86.03 & 0.872 \\
\hline $\mathrm{AA}$ & 17821.81 & 38.33 & 43.24 & 88.97 & 0.8465 \\
\hline $\mathrm{AB}$ & 17667.66 & 34.47 & 45.27 & 93.38 & 0.8954 \\
\hline $\mathrm{AC}$ & 17320.73 & 30.63 & 47.65 & 92.65 & 0.9253 \\
\hline
\end{tabular}

DEA are provided in Table 7 . In addition, the positions of the DMUs in the Pareto front are specified in Figure 11. In Figure 12, a comparison is made between the efficiency of layouts. Layouts A, C, D, L, Q, and $\mathrm{Y}$ are the most efficient ones, shown in Figures 13-18, and their efficiency is 1 . These layouts provide higher safety levels due to the cost paid for transportation.

\section{Concluding remarks}

In this article, two new multi-objective algorithms were introduced for solving construction site layout problems, which are of multi-objective nature. These algorithms are named NSCBO and ENSCBO which are working based on two recently developed metaheuristic algorithms: $\mathrm{CBO}$ and ECBO. The energy and momentum laws of physics, in the case of onedimensional collision between bodies, form the basis of the standard algorithms. In order to evaluate the performance of algorithms, one case study was considered and the algorithms were applied to the site layout planning. The results obtained were compared with those of the MOPSO algorithm, demonstrating an acceptable development in finding better Pareto front 


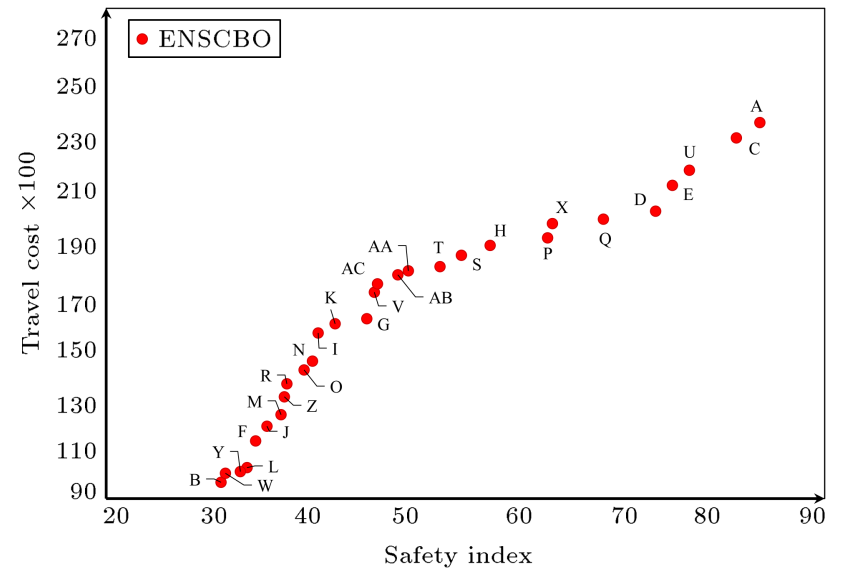

Figure 11. Alternative layouts.

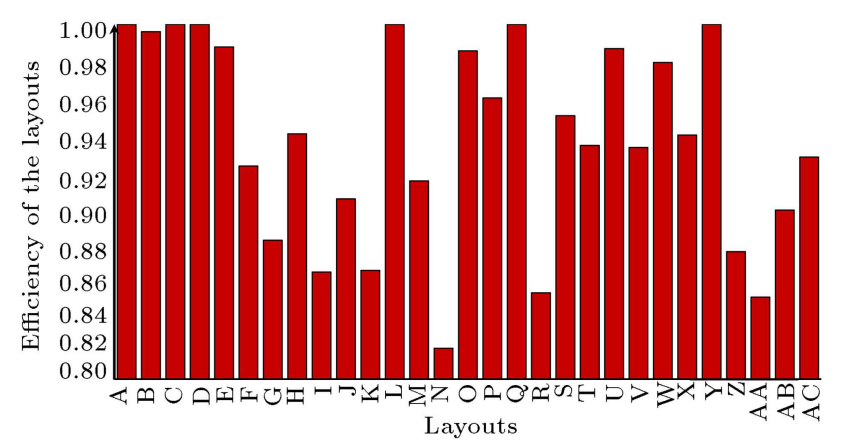

Figure 12. Comparison of the efficiency of the layouts.

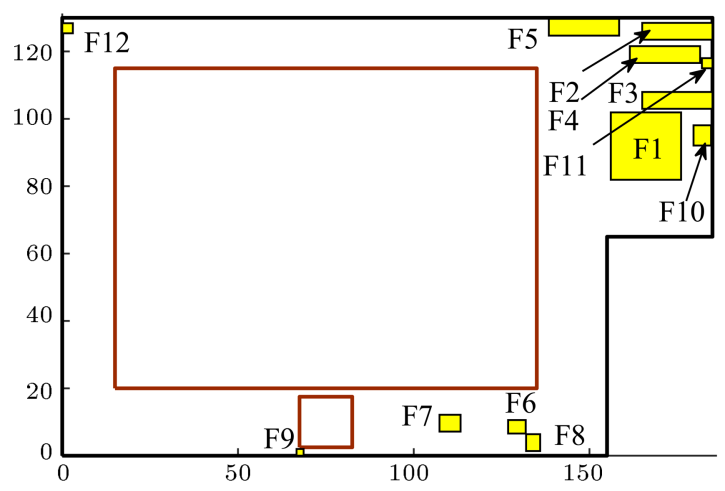

Figure 13. Layout A.

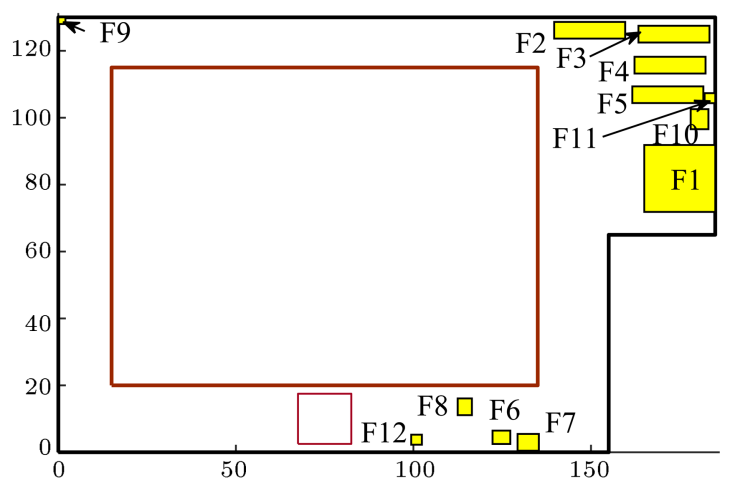

Figure 14. Layout C.

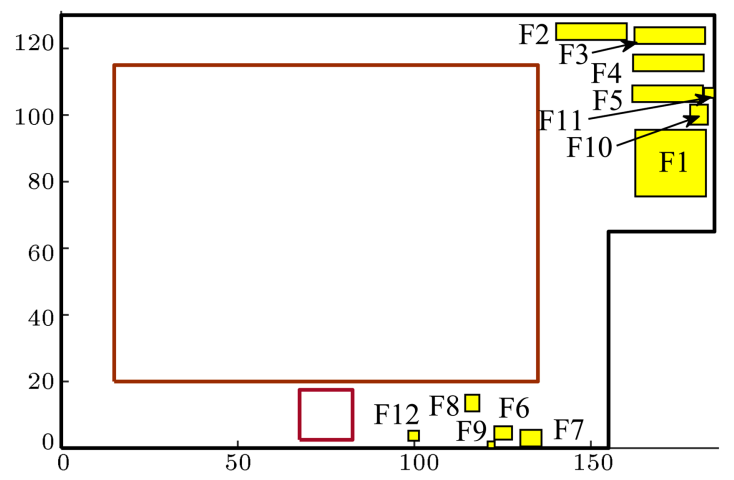

Figure 15. Layout D.

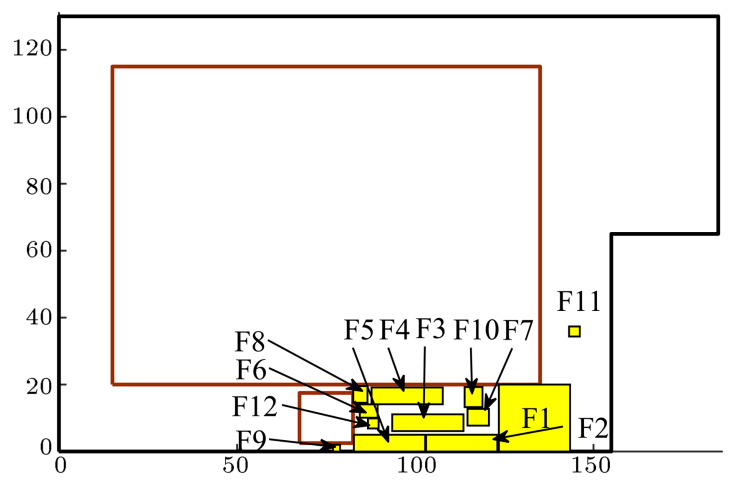

Figure 16. Layout L.

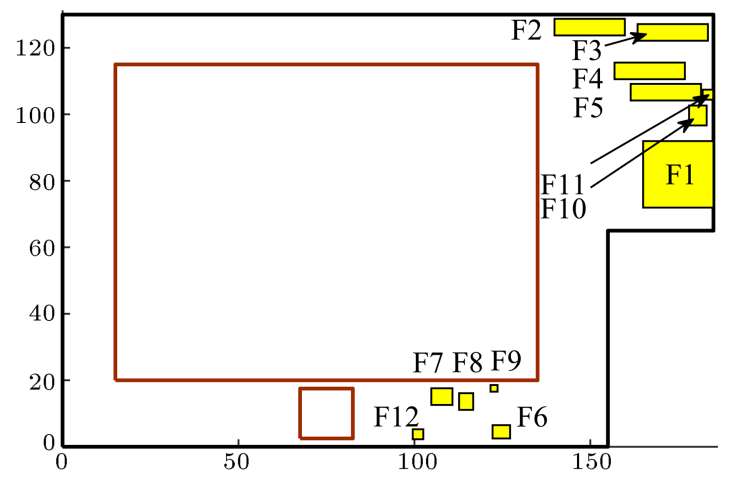

Figure 17. Layout Q.

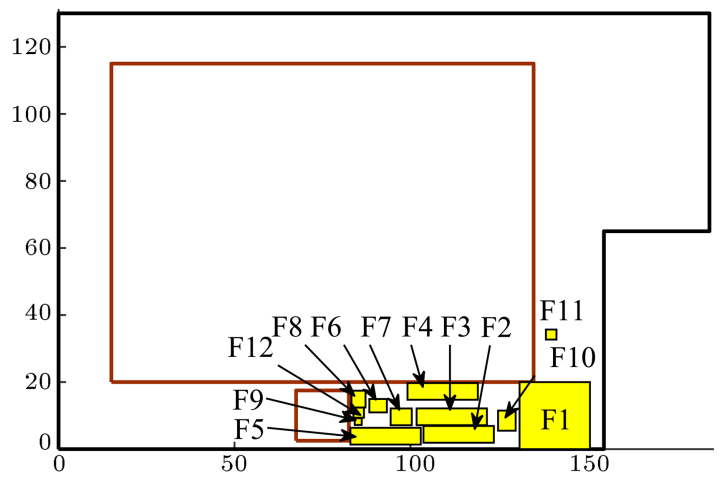

Figure 18. Layout Y. 
and much better layouts. Through the DEA method, the efficiency of the found layouts was examined and the efficient layouts were determined. This method is useful for modelling with multiple inputs and outputs. In this example, transportation cost was considered as an input and safety factors were taken as the outputs. This approach is a valuable tool for site managers to select the best layouts among existing alternatives. The presented algorithms can also be utilized for other multi-objective problems.

\section{References}

1. Sadeghpour, F. and Andayesh, M. "The constructs of site layout modeling: an overview", Canad. J. Civil Eng., 42(3), pp. 199-212 (2015).

2. Tommelein, I.D., Levitt, R.E., and Hayes-Roth, B. "Sight plan model for site layout", Knowl Creat Diffus Util., 118(4), pp. 749-766 (1991).

3. Li, H. and Love, P.E. "Genetic search for solving construction site-level unequal-area facility layout problems", Automat Construct., 9(2), pp. 217-226 (2000).

4. Lien, L.-C. and Cheng, M.-Y. "A hybrid swarm intelligence based particle-bee algorithm for construction site layout optimization", Expert Syst Applic., 39(10), pp. 9642-9650 (2012).

5. For, L., Around, R., Tam, B.C.M., Tong, T.K.L., and Chan, W.K.W. "Genetic algorithm for optimizing supply locations around tower crane", J. Construct Eng. Manag., 127(4), pp. 315-321 (2001).

6. Cheung, S.O. Tong, T.K.L., and Tam, C.M. "Site precast yard layout arrangement through genetic algorithms", Automat Construct., 11, pp. 35-46 (2002).

7. Xu, J. and Li, Z. "Multi-objective dynamic construction site layout planning in fuzzy random environment", Automat Construct., 27, pp. 155-169 (2012).

8. Yahya, M. and Saka, M.P. "Construction site layout planning using multi-objective artificial bee colony algorithm with Levy flights", Automat Construct., 38, pp. 14-29 (2014).

9. Hammad, A.W.A. Akbarnezhad, A., and Rey, D. "A multi-objective mixed integer nonlinear programming model for construction site layout planning to minimise noise pollution and transport costs", Automat Construct., 61, pp. 73-85 (2016).

10. El-Rayes, K., Asce, M., and Khalafallah, A. "Tradeoff between safety and cost in planning construction site layouts", J. Constuct Eng. Manag., 131(11), pp. 1186-1195 (2005).

11. Yeh, I.-C. "Architectural layout optimization using annealed neural network", Automat Construct., 15(4), pp. 531-539 (2006).

12. Lam, K.C., Tang, C.M., and Lee, W.C. "Application of the entropy technique and genetic algorithms to construction site layout planning of medium-size projects", Construct Manag Econom., 23(2), pp. 127145 (2005).
13. Calis, G. and Yuksel, O. "An improved ant colony optimization algorithm for construction site layout problems", J. Build Construct Plan Res., 3, pp. 221232 (2015).

14. Lam, K., Ning, X., and Ng, T. "The application of the ant colony optimization algorithm to the construction site layout planning problem", Construct Manag Econom., 25(4), pp. 359-374 (2007).

15. Adrian, A.M., Utamima, A., and Wang, K.-J. "A comparative study of GA, PSO and ACO for solving construction site layout optimization", KSCE J. Civil Eng., 19(3), pp. 520-527 (2014).

16. Zhang, H. and Wang, J.Y. "Particle swarm optimization for construction site unequal-area layout", $J$. Construct Eng. Manag., 134(9), pp. 739-748 (2008).

17. Lien, L.-C. and Cheng, M.-Y. "A hybrid swarm intelligence based particle-bee algorithm for construction site layout optimization", Expert Syst. Applic., 39(10), pp. 9642-9650 (2012).

18. Kaveh, A., Shakouri Mahmud Abadi, A., and Zolfaghari Moghaddam, S. "An adapted harmony search based algorithm for facility layout optimization", Int. J. Civil Eng., 10(1), pp. 1-6 (2012).

19. Kaveh, A., Khanzadi, M., Alipour, M., and Moghaddam, M.R. "Construction site layout planning problem using two new meta-heuristic algorithms", Iranian $J$. Sci. Technol, Civil Eng. Trans., 40(4), pp. 263-275 (2016).

20. Ning, X., Lam, K.C., and Lam, M.C.K. "A decisionmaking system for construction site layout planning", Autom Construct., 20(4), pp. 459-473 (2011).

21. Azadeh, A., Motevali Haghighi, S., Asadzadeh, S.M., and Saedi, H. "A new approach for layout optimization in maintenance workshops with safety factors: The case of a gas transmission unit", J. Loss Prevent Proc. Indust., 26(6), pp. 1457-1465 (2013).

22. Kaveh, A. and Mahdavi, V.R. "Colliding bodies optimization: A novel meta-heuristic method", Comput Struct., 139, pp. 18-27 (2014).

23. Kaveh, A. and Ilchi Ghazaan, M. "Enhanced colliding bodies optimization for design problems with continuous and discrete variables", Adv. Eng. Softw., 77, pp. 66-75, (2014).

24. Deb, K., Pratap, A., Agarwal, S., and Meyarivan, T. "A fast and elitist multiobjective genetic algorithm: NSGA-II", IEEE Trans Evol Comput., 6(2), pp. 182197 (2002).

25. Kaveh, A., Advances in Metaheuristic Algorithms for Optimal Design of Structures, Springer International Publishing, Switzerland, 2nd edition, (2017).

26. Kaveh, A., Applications of Metaheuristic Optimization Algorithms in Civil Engineering, Springer, Switzerland (2017). 
27. Farrell, M.J. "The measurement of productive efficiency", J.R. Stat. Soc. Ser. A, 120(3), pp. 253-290 (1957).

28. Charnes, A. Cooper, W.W., and Rhodes, E. "Measuring the efficiency of decision making units", European J. Oper. Res., 2(6), pp. 429-444 (1978).

\section{Biographies}

Ali Kaveh was born in 1948 in Tabriz, Iran. After graduation from the Department of Civil Engineering in the University of Tabriz in 1969, he continued his studies on Structures at Imperial College of Science and Technology at London University and received his MSc, DIC, and PhD degrees in 1970 and 1974, respectively. He then joined the Iran University of Science and Technology. Professor Kaveh is the author of 540 papers published in international journals and 145 papers presented at national and international conferences. He has authored 23 books in Persian and 10 books in English published by Wiley, Research Studies Press, American Mechanical Society and Springer.

Mohammad Rastegar Moghaddam was born December 31, 1991 in Yazd. He is an MSc candidate at the Department of Civil Engineering in the Iran University of Science and Technology, Iran. He received his BSc and MSc degree in Civil Engineering from Iran University of Science and Technology in 2014 and 2016. His main expertise and experience are in the field of construction management, labor productivity, and project scheduling by using optimization and simulation methods.

Mostafa Khanzadi is an Associate Professor of Civil Engineering with over 25 years of professional experience in civil and structural engineering. His main expertise and experience are in the fields of structural analysis, concrete technology, and construction management. 